\title{
Prospective study of the value of necropsy examination in early death after cardiac surgery
}

\author{
A H S Lee, B T Borek, P J Gallagher, R Saunders, R K Lamb, S A Livesey, V T Tsang, \\ J L Monro
}

\begin{abstract}
Objective-To assess the value of necropsy examination in patients dying soon after cardiac surgery, particularly the proportion of clinical questions answered by the necropsy, the frequency of major unexpected findings, and the limitations of the procedure.

Design-A three year prospective study of necropsy examinations in adult patients dying before discharge or within 30 days of cardiac surgery performed under cardiopulmonary bypass in one hospital.

Setting-Tertiary referral centre.

Results-123 of 2781 patients $(4 \cdot 4 \%)$ died in the early postoperative period, and necropsy examination was performed in 108 of these $(88 \%)$. The mortality after emergency procedures (18\%) was much higher than after routine operations $(2 \cdot 6 \%)$. The main causes of death were cardiac failure (52\%), haemorrhage $(14 \%)$, cerebral disease $(6 \%)$, and pulmonary emboli (5\%). The necropsy changed the stated cause of death in 16 patients (15\%), and answered clinical questions in 24 of 38 patients. In 15 patients necropsy examination did not provide a full explanation of death. Most of these patients died of cardiac failure soon after surgery or were sudden unexpected deaths.

Conclusions-Necropsy examination in patients dying early after cardiac surgery is valuable as it answers the majority of clinical questions, and shows unexpected findings in a significant proportion of cases.
\end{abstract}

Department of

Pathology,

University Hospitals

Southampton, United

Kingdom

A H S Lee

B T Borek

P J Gallagher

Wessex Cardiothoracic Centre

R Saunders

R K Lamb

S A Livesey

V T Tsang

J L Monro

Correspondence to:

A H S Lee, University

Department of Pathology,

Mailpoint 813, Level E,

South Block, Southampton

General Hospital,

Southampton SO16 6YD

United Kingdom.

Accepted for publication 6 May 1997
(Heart 1997;78:34-38)

Keywords: cardiac surgery; necropsy

The value of necropsy has been investigated in unselected patients, but we are not aware of any such studies of patients dying after cardiac surgery. This study was prompted by the impression among general pathologists in our hospital that necropsy examinations in patients dying early after cardiac surgery were often unrewarding. The aim of the study was to answer three questions: (1) How often does the necropsy in such patients answer the clinical questions? (2) What is the frequency of major unexpected findings? (3) What are the limitations of necropsy in these patients? We aimed to achieve as high a necropsy rate as possible to ensure the results were representative.
Methods

We studied prospectively all early deaths after cardiac surgery under cardiopulmonary bypass performed in the Wessex Cardiothoracic Centre over a three year period from August 1991 to July 1994. Early death was defined as death within 30 days of surgery, or before discharge from the Wessex Cardiothoracic Centre. Only adults aged 16 years or over were studied. The policy of the unit is to request a necropsy examination on all early deaths. For all patients dying after discharge the following were reviewed: hospital case notes, necropsy report and histology, and if relevant general practitioner records.

Cardiac failure was a clinicopathological diagnosis, defined as failure of the left ventricle resulting in pulmonary oedema. Most patients with cardiac failure had hypotension and oliguria, and were receiving inotropes or had an intra-aortic balloon pump. We recognise the problem of cardiac failure as a pathological diagnosis, in that it does not equate with a structural lesion. Where possible the diagnosis of cardiac failure was qualified with a cause. Preoperative cardiac failure as a cause of death was defined to include patients who were receiving inotropes, or had an intra-aortic balloon pump, or no spontaneous cardiac output when they went to theatre, and in whom cardiac failure persisted after coming off cardiopulmonary bypass until death. Perioperative or postoperative cardiac failure was diagnosed if there were clinical features of cardiac failure developing during or after surgery and evidence of a new pathological change (infarction or contraction band necrosis) at necropsy. Haemorrhage as a cause of death required at least $400 \mathrm{ml}$ of blood loss. "Sudden deaths" included patients who were found dead or died within an hour of the onset of symptoms after an initially uncomplicated postoperative course. In sudden unexplained deaths necropsy examination gave no definite cause of death.

In necropsies performed by the authors, a minimum of five sections of ventricular myocardium were taken: right ventricle, interventricular septum, and anterior, lateral, and posterior left ventricle. In hearts with bypass grafts, we took sections of the grafts including distal anastomoses, and sections of the myocardium supplied. Necrosis was diagnosed using haematoxylin and eosin sections. No enzymatic methods were used.

The approximate incidence of different causes of deaths was compared in patients undergoing emergency and non-emergency procedures. Patients who did not have a 
Table 1 Early mortality after different procedures

\begin{tabular}{llcc}
\hline & \multicolumn{2}{l}{ Deaths:operations (early mortality) } \\
\cline { 2 - 4 } Procedure & Non-emergency & Emergency & All procedures \\
\hline Coronary artery bypass grafts & $23: 1423(1 \cdot 6 \%)$ & $17: 153(11 \%)$ & $40: 1576(2 \cdot 5 \%)$ \\
Aortic valve replacement + CABG & $10: 195(5 \%)$ & $2: 10(20 \%)$ & $12: 205(6 \%)$ \\
Aortic valve replacement & $7: 386(2 \%)$ & $6: 41(15 \%)$ & $13: 427(3 \%)$ \\
Mitral valve replacement & $7: 102(7 \%)$ & $4: 16(25 \%)$ & $11: 118(9 \%)$ \\
Aortic and mitral valve replacements & $1: 37(3 \%)$ & $1: 7(14 \%)$ & $2: 44(5 \%)$ \\
Repair of acquired ventricular septal defect \pm CABG & $15: 257(5 \cdot 8 \%)$ & $14: 37(38 \%)$ & $14: 37(38 \%)$ \\
Other procedures (acquired disease) & $15: 61(25 \%)$ & $30: 318(9 \cdot 4 \%)$ \\
Congenital heart disease & $1: 56(2 \%)$ & - & $1: 56(2 \%)$ \\
All procedures & $64: 2456(2 \cdot 6 \%)$ & $59: 325(18 \%)$ & $123: 2781(4 \cdot 4 \%)$ \\
\hline
\end{tabular}

CABG, coronary artery bypass grafts.

necropsy examination were excluded. Relative risks were calculated and comparisons made using the Fisher exact test test.

\section{Results}

Over the three year period from August 1991 to July 1994, 2781 adult patients underwent cardiac surgery on cardiopulmonary bypass. Of these, 123 died in the early postoperative period. The mortality after emergency procedures $(18 \%)$ was much higher than after routine operations $(2 \cdot 6 \%)$. The early mortality after selected procedures is given in table 1 .

Necropsy examination was performed in 108 of the 123 early deaths $(88 \%)$. The necropsy rate for patients dying in Southampton was $97 / 107$ (91\%), and for patients dying after discharge 11/16 (69\%). Of the 97 patients having a necropsy in Southampton, 85 were performed or reviewed by AHSL, BTB, or PJG. Half the early deaths were in the first postoperative week. The necropsy rate was high in patients dying within three weeks of surgery (94\%), but declined after this $(61 \%)$.

\section{CAUSES OF DEATH \\ Cardiac failure}

Cardiac failure was the most common mode of death (56/108) (table 2). An underlying cause was established in 48 patients. The most common predisposing cause of preoperative heart failure was preoperative infarction, and 22 of these 27 patients had emergency surgery. This was particularly common in patients undergoing emergency coronary artery bypass grafting or repair of a postinfarction ventricular septal defect. Nine of the 11 patients with preoperative cardiac failure due to valvar disease had emergency valvar surgery. Seven of the eight patients with perioperative cardiac failure had perioperative infarction or coronary artery occlusion after undergoing coronary artery bypass grafting.

\section{Haemorrhage}

Haemorrhage at the site of a procedure was the cause of death in 15 patients: aortic dissection (2), aortotomy site (1), right atrial cannulation site (1), coarctation repair anastomosis (1), detached distal anastomosis of graft to coronary artery (3), side branch of saphenous vein graft (1); and related to mitral valve replacement, in two around the mitral valve and in one in the lateral left ventricle below the mitral valve. Three deaths were related to non-cardiac procedures: Swan-Ganz catheter causing pulmonary artery rupture (1), haemorrhage from the femoral artery (1), and rupture of the common iliac artery (1), both the latter after insertion of an intra-aortic balloon pump.

\section{Pulmonary emboli}

Five of the six patients dying of pulmonary emboli had undergone coronary artery bypass grafting. Four of these five had venous thrombosis of the leg: in three in the leg from which the saphenous vein grafts were taken; in one, the side of the venous thrombosis was not stated by the pathologist; in the fifth patient no venous thrombosis was found.

\section{Other causes of death}

Cerebral causes of death included infarction (3), haemorrhage (3) and anoxic damage (1). Infection was not a common cause of death: pneumonia (2), wound infection and septicaemia (1), and endocarditis in a patient who had valve replacement for endocarditis (1). Gastrointestinal causes of death included perforated duodenal ulcer (1) and upper gastrointestinal haemorrhage (3).

Table 2 Causes of death according to operation

\begin{tabular}{|c|c|c|c|c|c|c|c|c|c|c|c|c|c|c|}
\hline \multirow[b]{3}{*}{ Operation } & \multicolumn{5}{|c|}{ Cardiac causes } & \multirow{3}{*}{$\begin{array}{l}\text { Sudden } \\
\text { unexplained } \\
\text { death }\end{array}$} & \multirow{3}{*}{$\begin{array}{l}\text { Haemor- } \\
\text { rhage at } \\
\text { site of } \\
\text { procedure }\end{array}$} & \multirow{3}{*}{$\begin{array}{l}\text { Infec- } \\
\text { tion }\end{array}$} & \multirow{3}{*}{$\begin{array}{l}\text { Pulm- } \\
\text { onary } \\
\text { embolus }\end{array}$} & \multirow{3}{*}{$\begin{array}{l}\text { Gastro- } \\
\text { intestinal }\end{array}$} & \multirow[b]{3}{*}{ Cerebral } & \multirow[b]{3}{*}{ Misc } & \multirow[b]{3}{*}{ No PM } & \multirow[b]{3}{*}{ Total } \\
\hline & \multicolumn{2}{|c|}{ Preoperative } & \multirow{2}{*}{$\begin{array}{l}\text { Peri/postop } \\
\text { infarct or } \\
\text { coronary } \\
\text { occlusion }\end{array}$} & \multirow[b]{2}{*}{ Misc } & \multirow{2}{*}{$\begin{array}{l}\text { Unexplained } \\
\text { cardiac } \\
\text { failure }\end{array}$} & & & & & & & & & \\
\hline & Infarct & Valvar & & & & & & & & & & & & \\
\hline $\begin{array}{l}\text { CABG } \\
\text { Valve } \\
\text { replacement(s) }\end{array}$ & 9 & & 5 & & 5 & 3 & 4 & 2 & 5 & & 1 & 2 & 4 & 40 \\
\hline $\begin{array}{l}\text { or repair } \\
\text { Other }\end{array}$ & $\begin{array}{r}4 \\
14\end{array}$ & 11 & $\begin{array}{l}1 \\
2\end{array}$ & 2 & $\begin{array}{l}1 \\
2\end{array}$ & 2 & $\begin{array}{l}9 \\
2\end{array}$ & 2 & 1 & $\begin{array}{l}2 \\
2\end{array}$ & $\begin{array}{l}4 \\
2\end{array}$ & $\begin{array}{l}5 \\
4\end{array}$ & $\begin{array}{l}8 \\
3\end{array}$ & $\begin{array}{l}51 \\
32\end{array}$ \\
\hline Total & 27 & 11 & 8 & 2 & 8 & 5 & 15 & 4 & 6 & 4 & 7 & 11 & 15 & 123 \\
\hline
\end{tabular}

CABG, coronary artery bypass grafts; Misc, miscellaneous; PM, necropsy examination.

$\star 17$ patients also had CABG. 
Table 3 Number of clinical questions answered by the necropsy examination

\begin{tabular}{lccc}
\hline & \multicolumn{2}{c}{ Answered by necropsy } & \\
\cline { 2 - 3 } Question & Yes & No & Total \\
\hline Cause of sudden death & 5 & 4 & 9 \\
Cause of postoperative hypotension & 10 & 9 & 19 \\
Cause of postoperative respiratory failure & 2 & 1 & 3 \\
Cause of convulsions & 1 & & 1 \\
Cause of pulmonary hypertension & 1 & & 1 \\
Source of haemorrhage & 5 & 14 & 38 \\
Total & 24 & \\
\hline
\end{tabular}

Miscellaneous causes included: adult respiratory distress syndrome (2), pulmonary hypertension (2), renal failure (1), complications of aortic dissection in patients having aortic replacement or repair (3), and toxic epidermal necrolysis (1). Also included in this group were two patients with undetermined cause of death: one with unexplained hypotension, and the other with unexplained respiratory failure.

\section{QUESTIONS ASKED BY CLINICIANS}

In 70 of the 108 patients who had a necropsy examination the clinicians had a confident diagnosis of the cause of death. Necropsy showed unexpected findings in four of these patients. There was clinical uncertainty about the cause of death in the remaining 38 patients (table 3 ). In some the questions were refining the cause of death, for example the source of haemorrhage. Necropsy answered these clinical questions in 24 of 38 patients.

Why did the patient die suddenly?

The cause of sudden death was found in five of nine patients (graft thrombosis (2), graft dehiscence, pulmonary embolism, and left ventricular rupture). The remaining four patients had unwitnessed sudden deaths, thus

Table 4 Premortem cause of death changed by necropsy examination

\begin{tabular}{|c|c|c|}
\hline No & Procedure & Mode of death and pathological findings \\
\hline 1 & CABG (R) & $\begin{array}{l}\text { Died day } 28 \text {. Chest pain thought to be cardiac. Necropsy } \\
\text { showed pulmonary embolism. }\end{array}$ \\
\hline 2 & $\begin{array}{l}\text { Aortic and mitral valve } \\
\text { replacements }(\mathbf{R})\end{array}$ & $\begin{array}{l}\text { Died day } 17 \text {. Haemorrhage from lateral left ventricle } \\
\text { below mitral valve. }\end{array}$ \\
\hline 3 & Aortic valve replacement $(\mathrm{E})$ & $\begin{array}{l}\text { Died day } 7 \text {. Extensive myocardial infarction due to } \\
\text { dissection of left main stem. }\end{array}$ \\
\hline 4 & Redo CABG (R) & $\begin{array}{l}\text { Died day } 5 \text {. Clinically thought to have infarction due to } \\
\text { graft thrombosis (seen at further reoperation). Necropsy } \\
\text { showed extensive contraction band necrosis thought to } \\
\text { be related to cardiopulmonary bypass. }\end{array}$ \\
\hline 5 & $\begin{array}{l}\text { Aortic valve replacement } \\
+ \text { CABG (E) }\end{array}$ & $\begin{array}{l}\text { Died after } 4 \text { hours. Clinically thought to have } \\
\text { pulmonary oedema. Necropsy showed pneumonia with } \\
\text { abscesses. }\end{array}$ \\
\hline 6 & $\begin{array}{l}\text { Redo CABG + resection left } \\
\text { ventricular aneurysm }(R)\end{array}$ & $\begin{array}{l}\text { Died day 2. Preoperative infarction not diagnosed in } \\
\text { life. }\end{array}$ \\
\hline 7 & $\begin{array}{l}\text { CABG + resection of left } \\
\text { ventricular aneurysm }(R)\end{array}$ & Died day 9. Saphenous vein graft thrombosis. \\
\hline 8 & Aortic valve replacement $(\mathbf{R})$ & $\begin{array}{l}\text { Sudden death day } 10 \text {. Clinically thought to be } \\
\text { pulmonary embolus, but not confirmed. }\end{array}$ \\
\hline $\begin{array}{r}9 \\
10\end{array}$ & $\begin{array}{l}\text { CABG (E) } \\
\text { CABG (E) }\end{array}$ & $\begin{array}{l}\text { Died day 16. Myocardial infarction not diagnosed in life. } \\
\text { Died day 16. Clinically had bowel perforation. Necropsy } \\
\text { showed pulmonary embolism. }\end{array}$ \\
\hline 11 & $\begin{array}{l}\text { Aortic valve replacement } \\
+ \text { CABG (R) }\end{array}$ & $\begin{array}{l}\text { Died day } 22 \text {. Haemorrhage from saphenous vein } \\
\text { graft-coronary artery anastomosis. }\end{array}$ \\
\hline 12 & Mitral valve replacement $(R)$ & $\begin{array}{l}\text { Died day 4. Clinically had convulsions. Necropsy } \\
\text { showed subarachnoid haemorrhage. }\end{array}$ \\
\hline 13 & CABG (E) & $\begin{array}{l}\text { Died day } 10 \text {. Graft thrombosis and perioperative } \\
\text { infarction. }\end{array}$ \\
\hline 14 & $\begin{array}{l}\text { Repair of acquired VSD + } \\
\text { cardiac rupture, } \\
+ \text { CABG (E) }\end{array}$ & $\begin{array}{l}\text { Died day 22. Hypotension attributed to cardiac failure. } \\
\text { Abdominal pain not investigated. Necropsy showed } \\
\text { perforated duodenal ulcer. }\end{array}$ \\
\hline 15 & $\begin{array}{l}\text { CABG + resection of left } \\
\text { ventricular aneurysm }(R)\end{array}$ & Inflammation in graft wall with thrombosis, day 1 . \\
\hline 16 & Mitral valve replacement $(R)$ & $\begin{array}{l}\text { Sudden hypotension and death day } 33 \text {. Haemorrhage } \\
\text { from duodenal ulcer. }\end{array}$ \\
\hline
\end{tabular}

CABG, coronary artery bypass grafts; $E$, emergency; $R$, routine; VSD, ventricular septal defect; VT, ventricular tachycardia. an arrhythmia could not be excluded. All had cardiac pathology as a potential cause of an arrhythmia: myocardial infarction in three (recent in one and healed in two) and hypertrophy with fibrosis in one. In addition there was one patient who was clinically thought to have a pulmonary embolus, but this was not confirmed at necropsy. His deterioration was witnessed and was not associated with an arrhythmia. Necropsy showed marked left ventricular hypertrophy with fibrosis due to aortic stenosis. Thus there were five sudden unexplained deaths in total.

\section{Why was there postoperative hypotension?}

This was explained by necropsy in 10 of the 19 patients and was largely due to myocardial necrosis or haemorrhage. In eight patients there was incompletely explained cardiac failure: there were no new pathological changes to explain the cardiac failure. The procedure was an emergency in four, and seven had coronary artery bypass grafting. Six patients died soon after surgery (five on the first postoperative day and one on the second). In some of those dying soon after surgery there was strong clinical evidence of acute infarction (one patient showed loss of anteroapical contraction in theatre, and another developed new anteroseptal $Q$ waves on the electrocardiogram), but no new infarcts were shown at necropsy. The other two patients with unexplained cardiac failure died on the 12th and 29th days after surgery. Both had old myocardial infarction, but no new pathological changes. The other patient with unexplained hypotension had an initially uncomplicated recovery from aortic valve replacement. He was readmitted with hypotension on day 12 , and died a few hours later. The clinical diagnosis was septic shock, but blood cultures were negative. There was no pulmonary oedema on the chest $x$ ray. No new pathology was found at necropsy.

Why was there postoperative respiratory failure? A pathological cause was found in two patients (adult respiratory distress syndrome), but in the third patient a clinical diagnosis of brainstem stroke was not confirmed and there was no pulmonary pathology.

\section{CAUSE OF DEATH CHANGED BY NECROPSY}

EXAMINATION

The necropsy changed the cause of death in 16 patients $(15 \%)$ (table 4 ). Of these major discrepancies, knowledge of the diagnosis before death would have affected management and perhaps survival in five or six patients. Myocardial infarction (3), haemorrhage (2), pulmonary emboli (2), and duodenal ulcers (2) were the most common unsuspected findings.

INCOMPLETE CAUSES OF DEATH

At necropsy a complete or certain cause of death was not possible to define in 15 patients. Most were unexplained cardiac failure (8) or sudden deaths (5). One had unexplained hypotension, and one had unexplained respiratory failure. These patients have all been described above. 


\section{HISTOLOGY}

Histology was important in establishing the cause of death in 13 patients. We found histology to be of particular value in the diagnosis and dating of myocardial infarction: several cases interpreted macroscopically as acute infarction had no histological evidence of infarction. It was also useful in diagnosing adult respiratory distress syndrome, pneumonia, and pulmonary hypertension.

\section{EMERGENCY $v$ ROUTINE PROCEDURES}

Preoperative cardiac failure was a more common cause of death after emergency procedures (relative risk 33, $P<<0.001$ ). This was true for preoperative cardiac failure due to both infarction (particularly in coronary artery bypass grafts) and valvar heart disease (after valve replacements). The following were also more common causes of death after emergency procedures: unexplained cardiac failure (relative risk $7 \cdot 6, \mathrm{P}=0.009$ ), haemorrhage (relative risk $=3.8, \mathrm{P}=0.02$ ), and cerebral causes (relative risk 10, $P=0.002$ ).

\section{Discussion}

We studied the necropsy findings in 108 of $123(88 \%)$ patients who died in the early postoperative period after cardiac surgery and found that the main causes of death were cardiac failure $(52 \%)$, haemorrhage $(14 \%)$, pulmonary emboli (5\%), and cerebrovascular disease $(6 \%)$. Our overall mortality figure $(4.4 \%)$ is very similar to the national figures for 1991 and 1993. There is difficulty in defining cardiac failure, especially in the postoperative period. We used a clinicopathological definition, and pulmonary oedema was used as the major pathological feature, although this may be a terminal event. In the majority of patients there was substantial ischaemic or valvar heart disease. In other series of early death after coronary artery bypass grafting and valve replacement the proportion of deaths due to cardiac failure was higher, and the proportion for haemorrhage was lower. ${ }^{1-4}$ An exact comparison is difficult as necropsy rates, the total number of patients undergoing the procedures, and the proportion of emergency cases was not always mentioned in previous reports. Not surprisingly cardiac failure was a more common cause of death after emergency procedures. The same was also true for postoperative haemorrhage and death due to cerebral disease, but the numbers were smaller and the effects less marked.

The procedure with the highest mortality rate was repair of postinfarction ventricular septal defect. Fourteen of 37 patients (38\%) died, but all procedures were performed as emergencies in the immediate postinfarction period. All the deaths were the result of cardiac failure due to infarction. In 1987 Mann and Roberts suggested that inadequate closure of the defect, and a small residual left ventricular cavity, were two other important causes of death, ${ }^{5}$ but we found no evidence of these changes in our 14 cases. In the 1980 s Schoen suggested that perioperative infarction occurred in $50 \%$ of patients dying after coronary artery bypass grafts, ${ }^{2}$ but we found infarcts in only $10 \%$ of these cases. Extensive contraction band necrosis was seen in only two hearts in our study, and in one patient this was probably not related to surgery. It has been suggested that focal myocardial necrosis may reflect more widespread myocardial dysfunction. ${ }^{2}$ We did not find evidence to support this: for example we did not see it in the patients dying with unexplained cardiac failure soon after surgery. Fatal pulmonary emboli occurred in $0.3 \%$ of our patients, and as in previous series were less common after valve replacement operations than after coronary artery bypass grafting. ${ }^{6} 7$ There is conflicting evidence about whether deep venous thrombosis is more common in the leg from which saphenous vein grafts have been taken. ${ }^{67}$

Comparisons of premortem and postmortem diagnoses have been made since the beginning of the century. Despite modern laboratory and radiological investigations, important discrepancies continue to be found in $10-30 \%$ of cases, ${ }^{8-11}$ even in patients dying after surgery ${ }^{12}$ or on intensive care units. ${ }^{1314}$ One necropsy study of children with congenital heart disease, some of whom had undergone surgery, showed undiagnosed anomalies or surgical flaws in $17 \% .{ }^{15} \mathrm{We}$ are not aware of any such studies of adult cardiac surgery. In our series we found major discrepancies between the clinical and pathological cause of death in $15 \%$ of patients, and in $6 \%$ these may have affected survival or treatment. Necropsy series of unselected patients have found pulmonary emboli, myocardial infarction, and infections, especially pneumonia, and unusual infections are the conditions most often missed in life. ${ }^{910}$ Our unexpected findings are similar with the addition of haemorrhage.

The necropsy examination was successful in answering clinical questions in 24 of 38 patients. In all five patients where the source of haemorrhage was uncertain, a precise site was identified. However, the causes of sudden death and postoperative hypotension were identified in only half the patients. Others have had similar difficulties with unexplained sudden death and cardiac failure soon after surgery. ${ }^{12}$ In total we found an incomplete or uncertain cause of death in 15 of our 108 patients. This compares with rates of between $3 \%$ and $9 \%$ in necropsies on unselected patients, ${ }^{16} 17$ patients dying in intensive care units ${ }^{13}$ and "natural" sudden deaths. ${ }^{18}$ In early reports of necropsies after cardiac surgery, incomplete or indeterminate causes of death were found in $21 \%^{19}$ and $23 \%^{20}$ of deaths after coronary artery bypass grafting and $33 \%$ of valve replacements. ${ }^{21}$ More recently "no anatomic lesion" was found in $10 \%$ of deaths after coronary artery bypass grafting. ${ }^{2}$

Histology is an important part of the necropsy examination as the macroscopic diagnosis may be incorrect or incomplete in $8-25 \% .{ }^{1622} \mathrm{We}$ found histology to be of particular value in the diagnosis and dating of myocardial infarction and in pulmonary pathology, including bronchopneumonia. ${ }^{23}$ As 
yet there is no satisfactory histological method for the detection of early myocardial infarction, ischaemia, or metabolic dysfunction. Many unexplained deaths in this and other series occur soon after surgery, ${ }^{12}$ and may be due to these causes.

We have found that necropsy examination in patients dying early after cardiac surgery is valuable as it answers the majority of clinical questions and shows unexpected findings in a significant proportion of cases. Some deaths remain incompletely explained despite necropsy examination.

1 Jarvinen A, Manniko A, Ketonen P, Segerberg-Konttinen $M$, Luosto R. Surgical technique and operative mortality in coronary artery bypass. A postmortem analysis with castangiography. Scand $\mathcal{F}$ Thor Cardiovasc Surg 1989;23: 103-9.

2 Schoen FJ. Interventional and surgical cardiovascular pathology. Clinical correlations and basic principles. Philadelphia: WB Saunders, 1989:13-14, 82-3, 125-8.

3 Schoen FJ, Titus JL, Lawrie GM. Autopsy-determined causes of death after cardiac valve replacement. $¥ A M A$ 1983;249:899-902.

4 Ishibashi-Ueda $H$, Imakita $M$, Katsuragi $M$, Fujita $H$, Hao $H$, Yutani C. An analysis of autopsy findings in 108 patients who died after valve replacement. Virchows Arch $A$ Pathol Anat 1993;422:397-403.

5 Mann JM, Roberts WC. Cardiac morphologic observations after operative closure of acquired ventricular septal defect during acute myocardial infarction: analysis of 16 necropsy patients. Am 7 Cardiol 1987;60:981-7.

6 DeLaria GA, Hunter JA. Deep venous thrombosis. Implications after open heart surgery. Chest 1991;99:284-8.

7 Josa M, Siouffi SY, Silverman AB, Barsamian EM, Khuri SF, Sharma GVRK. Pulmonary embolism after cardiac surgery. $\mathcal{F}$ Am Coll Cardiol 1993;21:990-6.

8 Britton M. Diagnostic errors discovered at autopsy. Acta
Med Scand 1974;196:203-10.

9 Goldman L, Sayson R, Robbins S, Cohn LH, Bettman M, Weisberg M. The value of the autopsy in three medical eras. $N$ Engl f Med 1983;308:1000-5.

10 Battle RM, Pathak D, Humble CG, Key CR, Vanatta PR, Hill RB, et al. Factors influencing discrepancies between premortem and postmortem diagnoses. $\mathscr{f} A M A$ 1987;258: 339-44

11 Kirch W, Schafii C. Misdiagnosis at a university hospital in 4 medical eras. Report on 400 cases. Medicine 1996;75: $29-40$.

12 Stothert JC, Gbaanador G. Autopsy in general surgery practice. Am f Surg 1991;162:585-9.

13 Fernandez-Segoviano P, Lazaro A, Esteban A, Rubio JM, Iruretagoyena $\mathrm{JR}$. Autopsy as quality assurance in the intensive care unit. Crit Care Med 1988;16:683-5.

14 Stambouly J, Khan E, Boxer RA. Correlation between clinical diagnoses and autopsy findings in critically ill clinical diagnoses and autopsy finding

15 Russell GA, Berry PJ. Postmortem audit in a paediatric cardiology unit. F Clin Pathol 1989;42:912-18.

16 Schned AR, Mogielnicki P, Stauffer ME. A comprehensive quality assessment program on the autopsy service. $A m \mathcal{F}$ Clin Pathol 1986;86:133-8.

17 Veress B, Alafuzoff I. A retrospective analysis of clinical diagnoses and autopsy findings in 3042 cases during two different time periods. Hum Pathol 1994;25:140-5. 18 Thomas AC, Knapman PA, Krikler DM, Davies MJ. death. $B M \Im$ 1 1988;297:1453-6.

19 Bulkley BH, Hutchins GM. Myocardial consequences of coronary artery bypass graft surgery. The paradox of necrosis in areas of revascularisation Circulation 1977;56: 906-13.

20 Rose AG. State of the vein grafts, native coronary arteries, and myocardium and principal cause of death in patients dying after aortocoronary artery bypass grafting. Thorax dying after aort

21 Rose AG. Autopsy-determined causes of death following heart valve replacement. Am $\mathcal{F}$ Cardiovasc Pathol 1986;1: $39-46$.

22 Hartveit F. Clinical and post-mortem assessment of the cause of death. $\mathcal{F}$ Pathol 1977;123:193-210

23 Hunt CR, Benbow EW, Knox WF, McMahon RFT, McWilliam LJ. Can histopathologists diagnose bronchopneumonia? f Clin Pathol 1995;48:120-3. 